\title{
Minat Belajar Pendidikan Jasmani Pada Siswa Kelas V SD Negeri 107826 Pematang Sijonam Tahun Ajaran 2020/2021
}

\author{
Abdurrahman Yusuf Anjani Pjt ${ }^{1}$ Dewi Maya Sari ${ }^{2}$ \\ 1,2 Sekolah Tinggi Olahraga dan Kesehatan Bina Guna, Indonesia \\ Jl. Aluminium Raya No. 77, Tanjung Mulia, Medan, Sumatera Utara \\ Email : Dewimayasari@gmail.com
}

\begin{abstract}
ABSTRAK
Penelitian ini merupakan deskriptif kuantitatif, dengan metode survei, adapun teknik pengambilan datanya menggunakan angket. Survei berupa penelitian untuk mengetahui minat belajar pendidikan jasmani pada siswa kelas V SD negeri 107826 Pematang Sijonam Tahun ajaran 2020/2021. Populasi dalam penelitian ini yaitu siswa kelas V-A SD Negeri 107826 Pematang Sijonam yang berjumlah 42 siswa. Sedangkan sampel penelitian ini adalah seluruh populasi yang ada yakni berjumlah 42 orang siswa. Instrumen yang dipakai dalam penelitian ini adalah angket. Pada penelitian ini, penulis memilih angket tertutup sebagai instrumen dari pengumpulan data penelitian. Penskoran digunakan dengan menggunakan skala Likert dengan tiga alternatif jawaban, yaitu: setuju (S), kurang setuju (KS), dan tidak setuju (TS) Responden dapat memilih salah satu dari tiga alternatif jawaban yang disesuaikan dengan keadaan subjek. Hasil penelitian menunjukan bahwa minat belajar pendidikan jasmani siswa kelas V di SD Negeri 107826 Pematang Sijonam, berdasarkan nilai rata-rata, yaitu 62,88, minat belajar pendidikan jasmani siswa kelas V SD Negeri 107826 Pematang Sijonam dalam kategori "sedang", dari hasil penelitian juga diketahui siswa berada pada kategori "sangat rendah" sebesar 7,14\% (3 siswa), "rendah" sebesar 16,67\% (7 siswa), "sedang" sebesar 42,86\% (18 siswa), "tinggi" sebesar 26,19\% (11 siswa), dan "sangat tinggi" sebesar 7,14\% (3 siswa).
\end{abstract}

\section{Kata kunci: Minat Belajar, Pendidikan Jasmani}

\begin{abstract}
This research is quantitative descriptive, by survey method, as for the data retrieval technique using questionnaires. Survey in the form of research to find out the interest in studying physical education in grade V students of sd negeri 107826 Pematang Sijonam School year 2020/2021. The population in this study was grade V-A students of SD Negeri 107826 Pematang Sijonam which numbered 42 students. While the sample of this study is the entire population of 42 students. The instrument used in this study is a questionnaire. In this study, the authors chose closed polls as instruments for the collection of research data. Scoring is used using the Likert scale with three alternative answers, namely: agree (S), disagree (KS), and disagree (TS) Respondents can choose one of three alternative answers tailored to the subject's circumstances.

The results showed that the interest in studying physical education of grade $V$ students in SD Negeri 107826 Pematang Sijonam, based on the average score of 62.88, the interest in studying physical education of grade V students of SD Negeri 107826 Pematang Sijonam in the "moderate" category, from the results of the study also found students to be in the "very
\end{abstract}


low" category of 7.14\% (3 students), "low" by 16.67\% (7 students), "moderate" by $42.86 \%$ (18 students) , "high" at 26.19\% (11 students), and "very high" at 7.14\% (3 students).

\section{Keywords: Interest in Learning Physical Education}

\section{PENDAHULUAN}

Dalam aktivitas belajar pendidikan jasmani, setiap siswa memiliki minat yang berbeda, ada yang karena tuntutan orang tua, ada karena keinginan diri sendiri untuk meningkatkan ilmu pengetahuan, dan ada pula yang karena status atau gengsi sosial semata. Kondisi ini dipengaruhi oleh minat dari setiap siswa. Minat merupakan salah satu aspek yang ada pada diri manusia sedangkan minat belajar mata pelajaran pendidikan jasmani adalah kekuatan yang mendorong siswa untuk memperhatikan, merasa tertarik dan senang terhadap aktivitas belajar pendidikan jasmani sehingga mereka mau melakukan aktivitas belajar pendidikan jasmani dengan kemauan sendiri. Minat merupakan salah satu aspek psikis yang membantu dan mendorong seseorang untuk memenuhi kebutuhannya, maka minat harus ada dalam diri seseorang, sebab minat merupakan modal dasar untuk mencapai tujuan. Dengan demikian minat itu adalah modal yang paling awal sebelum dilakukan sesuatu yang diinginkan atau permulaan dari semua aktivitas. Misalnya saja seseorang yang menaruh minat terhadap pelajaran pendidikan jasmani akan mempunyai perhatian lebih dan keingintahuan yang lebih besar dari pada siswa lainnya. Berdasarkan observasi pendahuluan, melalui wawancara dengan guru pendidikan jasmani di SD Negeri 107826 Pematang Sijonam, terdapat fasilitas pembelajaran pendidikan jasmani seperti lapangan futsal, lapangan voli, dan lapangan sepak bola, Terdapat juga ruangan indoor di sekolah yang juga bisa digunakan kegiatan olahraga seperti senam lantai. Semua itu terdapat di halaman sekolah kecuali lapangan sepakbola terdapat agak jauh sekitar 100 meter dari sekolah. Kemudian dari hasil observasi ternyata tidak semua siswa aktif dalam mengikuti pelajaran pendidikan jasmani. Dari 30 orang siswa kelas V SD 107826 Pematang Sijonam, terlihat 20 orang siswa berminat mengikuti pendidikan jasmani, seperti serius memperhatikan materi yang disampaikan guru, serius mengikuti kegiatan praktek dilapangan, namun dari observasi juga terlihat 10 orang siswa yang malas-malasan dalam mengikuti pembelajaran pendidikan jasmani, ada yang kurang serius, bahkan ada diantaranya dengan berbagai alasan berusaha untuk tidak mengikuti pelajaran pendidikan jasmani. Ada saja siswa yang yang beralasan seperti tidak membawa baju, takut panas karena olahraganya di luar ruangan, kadang ada siswa yang berteduh di bawah pohon dan mengobrol dengan teman ketika pembelajaran pendidikan jasmani berlangsung.

Ada juga siswa yang malas melakukan kegiatan pelajaran penjas pada jam-jam pertama dengan alasan akan mengganggu konsentrasi belajar untuk mata pelajaran selanjutnya karena setelah melakukan kegiatan olahraga siswa tersebut merasa lelah dan ngantuk dan berakibat terganggunya konsentrasi belajar. Begitupun ketika melakukan pelajaran penjas pada jam-jam terakhir biasanya para siswa sudah agak malas untuk melakukannya karena beberapa faktor seperti panas terik matahari yang sudah mulai menyengat, oleh karenanya banyak siswa yang enggan melakukan pelajaran penjas apalagi siswa sekolah dasar yang sedang dalam proses masa puber dan proses pencarian jati diri sehingga mereka sangat memperhatikan penampilannya untuk bisa menarik perhatian lawan jenis atau alasan yang lainnya, dan merekapun menjadi tidak mau berlama-lama berolahraga di bawah terik matahari karena takut kulit mereka menjadi gelap bahkan hitam. 
Atau alasan lainya seperti kondisi tubuh yang sudah tidak segar lagi karena terkuras oleh aktifitas fisik dan kegiatan belajar yang menguras pikiran sehingga untuk melakukan kegiatan belajar penjas siswa sudah sangat tidak bergairah lagi. Ada pula sebagian siswa yang lebih senang melakukan kegiatan belajar penjas pada jam-jam terakhir dengan alasan setelah lelah berolahraga mereka bisa langsung pulang dan beristirahat di rumah dan rasa lelah mereka tidak mengganggu aktivitas lainnya karena sudah tidak ada lagi kegiatan belajar mengajar.

Jika masalah-masalah di atas tidak di pecahkan, di khawatirkan akan menjadikan pelajaran penjas menjadi kurang diminati atau bahkan jika sudah tidak diminati siswa akan menjadikan pemikiran para siswa bahwa pelajaran penjas hanya sebagai pelajaran pelengkap saja yang kehadiran pelajaran penjas hanya akan mengganggu mereka untuk lebih berfokus pada mata pelajaran yang lainnya, karena dinilai pelajaran penjas merupakan sesuatu yang menjenuhkan dan melelahkan saja.

\section{METODE PENELITIAN}

Penelitian ini merupakan deskriptif kuantitatif, dengan metode survei, adapun teknik pengambilan datanya menggunakan angket. Survei berupa penelitian untuk mengetahui minat belajar pendidikan jasmani pada siswa kelas V SD Negeri 107826 Pematang Sijonam Tahun ajaran 2020/2021. Skor yang diperoleh dari angket kemudian dianalisis dengan menggunakan teknik statistik deskriptif kuantitatif yang dituangkan dalam bentuk persentase. Populasi dalam penelitian ini yaitu siswa kelas V-A SD Negeri 107826 Pematang Sijonam yang berjumlah 42 siswa. Instrumen yang dipakai dalam penelitian ini adalah angket. Kuisioner digunakan untuk menyelidiki pendapat subjek mengenai suatu hal atau untuk mengungkapkan kepada responden. Menurut Suharsimi Arikunto (2010:128), “Angket atau kuisioner adalah sejumlah pertanyaan atau peryataan yang digunakan untuk memperoleh informasi sampel dalam arti laporan pribadinya, atau hal-hal yang ia ketahui."

Tabel. 3.1. Kisi-Kisi Angket

\begin{tabular}{|c|c|c|}
\hline Variabel & Indikator & No Item \\
\hline \multirow{4}{*}{$\begin{array}{l}\text { Minat belajar pendidikan } \\
\text { jasmani }\end{array}$} & 1. Perasaan senang & $1,2,3,4,5$ \\
\hline & $\begin{array}{ll}\text { 2. } & \text { Ketertarikan }\end{array}$ & $6,7,8,9,10$ \\
\hline & 3. Perhatian siswa & $11,12,13,14,15$ \\
\hline & 4. $\quad$ Keterlibatan siswa & $16,17,18,19,20$ \\
\hline
\end{tabular}

\section{HASIL DAN PEMBAHASAN}

Hasil

Penelitian ini dilaksanakan di SD Negeri 107826 Pematang Sijonam. Sampel dalam penelitian ini adalah siswa kelas V SD Negeri 107826 Pematang Sijonam yang berjumlah 42 siswa. Hasil penelitian ini dimaksudkan untuk menggambarkan data yaitu tentang seberapa tinggi minat siswa kelas V dalam mengikuti pembelajaran Pendidikan jasmani olahraga dan 
kesehatan di SD Negeri 107826 Pematang Sijonam, yang diungkapkan dengan angket yang berjumlah 20 butir. Hasil analisis data penelitian minat belajar pendidikan jasmani siswa kelas V di SD Negeri Negeri 107826 Pematang Sijonam dipaparkan sebagai berikut: Distribusi frekuensi data hasil penelitian tentang minat belajar pendidikan jasmani siswa kelas V di SD Negeri 107826 Pematang Sijonam didapat skor terendah (minimum) 47,00, skor tertinggi (maksimum) 74,00, rerata (mean) 62,88, nilai tengah (median) 62,50, standar deviasi (SD) 5,98.

\section{Distribusi Frekuensi Data Minat Belajar Pendidikan Jasmani}

\begin{tabular}{|c|c|}
\hline \multicolumn{2}{|c|}{ Statistik } \\
\hline $\mathrm{N}$ & 42 \\
\hline Mean & 62.8810 \\
\hline Median & 62.5000 \\
\hline Std. Deviation & 5.98047 \\
\hline Minimum & 47.00 \\
\hline Maximum & 74.00 \\
\hline
\end{tabular}

Tabel 2. Minat Belajar Pendidikan Jasmani

\begin{tabular}{|c|l|l|c|c|}
\hline No & \multicolumn{1}{|c|}{ Interval } & \multicolumn{1}{|c|}{ Kategori } & Frekuensi & $\%$ \\
\hline 1 & $71,85<\mathrm{X}$ & Sangat tinggi & 3 & 7,14 \\
\hline 2 & $65,87<\mathrm{X} \leq 71,85$ & Tinggi & 11 & 26,19 \\
\hline 3 & $59,89<\mathrm{X} \leq 65,87$ & Sedang & 18 & 42,86 \\
\hline 4 & $53,19<\mathrm{X} \leq 59,89$ & Rendah & 7 & 16,67 \\
\hline 5 & $\mathrm{X} \leq 53,91$ & Sangat rendah & 3 & 7,14 \\
\hline
\end{tabular}

\section{Minat Belajar Pendidikan Jasmani}

50

40

30

20

10

0
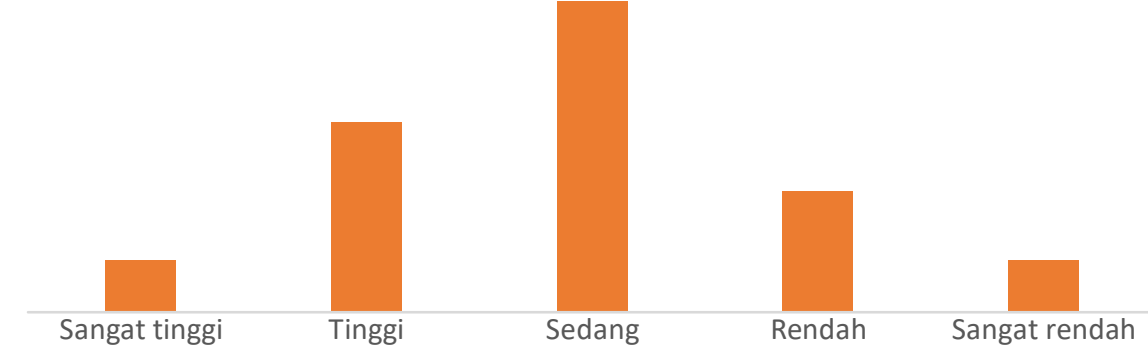
Berdasarkan tabel 4.2 dan gambar 1 di atas menunjukkan bahwa minat belajar pendidikan jasmani siswa kelas V di SD Negeri 107826 Pematang Sijonam berada pada kategori "sangat rendah" sebesar 7,14\% (3 siswa), "rendah" sebesar 16,67\% (7 siswa), "sedang" sebesar 42,86\% (18 siswa), "tinggi" sebesar 26,19\% (11 siswa), dan "sangat tinggi" sebesar 7,14\% (3 siswa). Berdasarkan nilai rata-rata, yaitu 62,88, minat belajar pendidikan jasmani siswa kelas V SD Negeri 107826 Pematang Sijonam dalam kategori "sedang".

\section{Pembahasan}

Minat siswa dalam mengikuti pembelajaran jasmani sangat berpengaruh terhadap keberhasilan pembelajaran yang dikemas oleh guru. Hal ini dikarenakan siswa sebagai pelaku pembelajaran menjadi bagian terpenting dalam keberhasilan pembelajaran. Sehingga pembelajaran harus dikemas sedemikian rupa dan berusaha menumbuhkan minat belajar siswa agar pembelajaran dapat berjalan dengan maksimal. Permasalahan yang sering muncul dalam pembelajaran pendidikan jasmani harus mampu diminimalisir oleh guru agar siswa dapat tertarik mengikuti pembelajaran pendidikan jasmani dengan aktif. Kendala mengatasi minat siswa mengikuti pendidikan jasmani yang beragam dari siswa maka guru penjas perlu pengemasan pembelajaran yang efektif sehingga mampu membangkitkan minat siswa dalam mengikuti pembelajaran. Minat kecenderungan dalam diri individu untuk tertarik pada subyek atau menyenangi suatu objek. Hal ini menunjukkan bahwa seberapa besar minat siswa dalam mengikuti pendidikan jasmani merupakan cerminan seberapa besar siswa tertarik terhadap pembelajaran pendidikan jasmani. Keadaan ini dapat dipengaruhi oleh faktor dari dalam maupun dari luar. Minat siswa yang tinggi akan tercermin dengan tingkat partisipasi siswa dalam pembelajaran pendidikan jasmani yang tinggi. Sebaliknya jika minat siswa rendah maka dapat tercermin dalam partisipasi siswa dalam pembelajaran yang rendah. Kondisi psikologis siswa menjadi patokan utama untuk seberapa besar minat siswa. dengan hal ini maka seorang guru harus mampu mengontrol dan menciptakan suasana pembelajaran yang meyenangkan dan menarik perhatian siswa dalam mengikuti pembelajaran. Hal ini menunjukkan bahwa peranan guru dan fasilitas pembelajaran lebih mempengaruhi siswa dibandingkan dengan perhatian, perasaan senang dan bentuk aktivitas siswa dalam pembelajaran. Peranan guru dalam pembelajaran sangatlah sentral untuk mengemas pembelajaran dan mengontrol kondisi kelas. Hal ini menunjukkan bahwa seorang guru harus mampu menciptakan suasana pembelajaran dengan memanfaatkan fasilitas dan mengontrol psikologis siswa agar siswa memiliki minat belajar yang tinggi. Minat belajar yang tinggi akan mambantu siswa untuk aktif dalam pembelajaran dan memiliki kesempatan untuk menguasai keterampilan yang diajarkan dan meraih prestasi belajar yang maksimal. Penjasorkes merupakan proses pendidikan yang bertujuan untuk mengembangkan dan meningkatkan individu yang direncanakan secara sistematik dalam mencapai tujuan pendidikan melalui aktivitas jasmani. Penelitian ini, minat siswa kelas V dalam mengikuti pembelajaran Pendidikan jasmani olahraga dan kesehatan di SD Negeri 107826 Pematang Sijonam masuk dalam kategori sedang.

\section{KESIMPULAN}

Berdasarkan hasil analisis data dan pembahasan dapat diambil kesimpulan, bahwa minat belajar pendidikan jasmani siswa V SD Negeri 107826 Pematang Sijonam berada pada 
kategori "sangat rendah" sebesar 7,14\% (3 siswa), "rendah" sebesar 16,67\% (7 siswa), "sedang" sebesar 42,86\% (18 siswa), "tinggi" sebesar 26,19\% (11 siswa), dan "sangat tinggi" sebesar 7,14\% (3 siswa). Dari hasil perhitungan dapat disimpulkan bahwa mayoritas minat belajar pendidikan jasmani siswa kela V SD Negeri 107826 Pematang Sijonam dalam kategori sedang.

\section{DAFTAR PUSTAKA}

Ahmadi, Abu dan Supriyono, Widodo. 2014. Psikologi Belajar. Jakarta : Rineka Cipta

Arikunto, Suharsimi. 2010. Prosedur Penelitian Suatu Pendekatan Praktik Edisi Revisi 5. Jakarta: Bima Aksara.

Aprial M, B. (2014). PENERAPAN MODEL PEMBELAJARAN BERBASIS MASALAH (PROBLEM BASED LEARNING) DENGAN PENDEKATAN SCIENTIFIC DALAM UPAYA MENINGKATKAN HASIL BELAJAR CHEST PASS DALAM PERMAINAN BOLA BASKET SISWA KELAS X SMA NEGERI 5 TANJUNG BALAI TAHUN AJARAN 2014/2015 (Doctoral dissertation, UNIMED).

Departemen Pendidikan dan Kebudayaan. 2006. Kamus Besar Bahasa Indonesia. Jakarta: Balai Pustaka

Gulo, W. 2012. Strategi Belajar Mengajar. Jakarta : Gramedia Widiasarana Indonesia

Helmy Firmansyah. 2009. Hubungan Motivasi Berprestasi Siswa dengan Hasil Belajar Pendidikan Jasmani. Jurnal JPJI

Hurlock Elizabeth B. 2005.. Perkembangan Anak. Jakarta: Renika Cipta.

Painun, dkk. 2004. Psikologi Perkembangan. Jakarta: Direktorat Jendral

Ladjid, Hafni. 2005. Pengembangan Kurikulum. Jakarta : Quantum Teaching

Samsuddin Poetra. 2008. Model Pembelajaran. Jakarta: Rineka Cipta

Sanjaya, Wina. 2008. Pembelajaran Dalam Implementasi Kurikulum Berbasis Kompetensi. Jakarta : Kencana Prenada Group

Slameto. 2010. Belajar dan Faktor-Faktor Yang Mempengaruhinya. Jakarta: Rineka Cipta.

Sudijandoko, Andun. 2010. Jurnal Pendidikan Jasmani Indonesia. Volume 7. Yogyakarta : FIK UNY

Sudijono, Anas. 2006. Pengantar Statistik Pendidikan. Jakarta: Raja Grafindo.

Sugiyono. 2009. Metode Penelitian Kuantitatif, Kualitatif Dan R\&D. Bandung: Alfabeta. 
Sukintaka. 2004. Teori Pendidikan Jasmani ; Filosofi Pembelajaran \& Masa Depan. Bandung: Nuansa Cendikia

Susworo. 2008. dalam Jurnal Pendidikan Jasmani Indonesia. Depdiknas

Suprapto Widodo, dan Mukhtar. 2003. Manajemen Berbasis Sekolah. Jakarta : Fifamas

Syarifudin, B. 2010. Panduan TA Keperawatan dan Kebidanan Dengan SPSS. Grafindo Litera Media.

Usman, Uzer. 2003. Menjadi Guru Profesional. Bandung : Remaja Rosdakarya

Yamin, Martinis. 2007. Desain Pembelajaran Berbasis Tingkat Satuan Pendidikan. Jakarta : Gaung Persada Press

Walgito, Bimo. 2003. Pengantar Psikologi Umum. Jakarta: Penerbit Andi 